\title{
Surgical nuances and placement of subgaleal drains for supratentorial procedures-a prospective analysis of efficacy and outcome in 150 craniotomies
}

\author{
Hussam Aldin Hamou ${ }^{1} \cdot$ Konstantin Kotliar ${ }^{2} \cdot$ Sonny Kian Tan ${ }^{1} \cdot$ Christel Wei $^{3} \cdot$ Blume Christian $^{1} \cdot$ Hans Clusmann $^{1}$. \\ Gerrit Alexander Schubert ${ }^{1} \cdot$ Walid Albanna ${ }^{1}$ (D)
}

Received: 27 July 2019 / Accepted: 20 December 2019/Published online: 15 January 2020

(C) The Author(s) 2020

\begin{abstract}
Background For supratentorial craniotomy, surgical access, and closure technique, including placement of subgaleal drains, may vary considerably. The influence of surgical nuances on postoperative complications such as cerebrospinal fluid leakage or impaired wound healing overall remains largely unclear. With this study, we are reporting our experiences and the impact of our clinical routines on outcome in a prospectively collected data set.

Method We prospectively observed 150 consecutive patients undergoing supratentorial craniotomy and recorded technical variables (type/length of incision, size of craniotomy, technique of dural and skin closure, type of dressing, and placement of subgaleal drains). Outcome variables (subgaleal hematoma/CSF collection, periorbital edema, impairment of wound healing, infection, and need for operative revision) were recorded at time of discharge and at late follow-up.

Results Early subgaleal fluid collection was observed in 36.7\% (2.8\% at the late follow-up), and impaired wound healing was recorded in $3.3 \%$ of all cases, with an overall need for operative revision of $6.7 \%$. Neither usage of dural sealants, lack of watertight dural closure, and presence of subgaleal drains, nor type of skin closure or dressing influenced outcome. Curved incisions, larger craniotomy, and tumor size, however, were associated with an increase in early CSF or hematoma collection ( $p<0.0001, p=0.001, p<0.01$ resp.), and larger craniotomy size was associated with longer persistence of subgaleal fluid collections $(p<0.05)$.

Conclusions Based on our setting, individual surgical nuances such as the type of dural closure and the use of subgaleal drains resulted in a comparable complication rate and outcome. Subgaleal fluid collections were frequently observed after supratentorial procedures, irrespective of the closing technique employed, and resolve spontaneously in the majority of cases without significant sequelae. Our results are limited due to the observational nature in our single-center study and need to be validated by supportive prospective randomized design.
\end{abstract}

Keywords Craniotomy $\cdot$ CSF fistula/leak · Dural closure · Infection · Subgaleal drainage

Gerrit Alexander Schubert and Walid Albanna contributed equally to this work.

Presentation at conference: Part of this study was presented at the 66th Annual Meeting of the German Society of Neurosurgery (DGNC), May/ 2015, Karlsruhe, Germany.

This article is part of the Topical Collection on Neurosurgery general

Electronic supplementary material The online version of this article (https://doi.org/10.1007/s00701-019-04196-6) contains supplementary material, which is available to authorized users.

Walid Albanna

walidalbanna@yahoo.de

1 Department of Neurosurgery, RWTH Aachen University, Pauwelsstr. 30, 52074 Aachen, Germany
2 Department of Medical Engineering and Technomathematics, FH Aachen University of Applied Sciences, Aachen, Germany

3 Department for Medical Statistics and Biomathematics, Medical Faculty Mannheim, Heidelberg University, Mannheim, Germany 


\section{Introduction}

For most intracranial neurosurgical procedures, there are numerous surgical nuances described in the literature, including variation of surgical access techniques, detailed descriptions and recommendations for dural closure, placement of the bone flap and/or surgical drains, and closure of the skin $[2,7,36$, $43,47,53]$. The individual choice of technique often depends on surgical experience, personal preference, and departmental standards. Adverse events, however, may still occur: postoperative infections [1, 5, 13, 16, 33, 37], wound dehiscence [4], and leakage of cerebrospinal fluid [31]. These can increase morbidity, prolong hospitalization, and may require surgical and medical intervention, thus increasing socioeconomic costs $[19,34]$.

Primary watertight dural closure has been suggested for reducing CSF leakage rate, and infections as well as impaired wound healing have been described in the absence of watertight closure [12, 29, 51], but these findings have been questioned by others [7]. Subgaleal fluid collections in general may protract wound healing, but prophylactic placement of drains to address those may also facilitate surgical site infections, secondary wound breakdown, or more serious complications such as infectious destruction of anatomical structures [41]. Active suction may even result in pseudohypoxic brain swelling and death [49].

Currently, there is no clear evidence to support specific recommendations for placement of subgaleal drains, as extremely variable execution of surgery complicates the conduction of randomized studies. While a certain technique is readily justified and implemented, an overly apodictical use of one technique over another may not necessarily result in a superior outcome.

It is the purpose of this single-center observational study to report our experiences of subgaleal drain placement in the context of supratentorial surgeries, utilized upon discretion of the individual treating physician.

\section{Methods}

\section{Patient selection}

For this prospective observational analysis, we consecutively recruited patients undergoing open supratentorial craniotomy between January 2014 and January 2016. Patients with intracranial tumor, intracranial hemorrhage, cerebrovascular pathology, or closed traumatic brain injury referred to our neurosurgical department were included. Patients with previous craniotomy or those requiring decompressive craniectomy, cases with previous or ongoing radiation or chemotherapy, and those in need of CSF diversion or drainage of an intracranial abscess were excluded. As part of this observational study and in addition to demographic data, individual surgical nuances (see below) were permitted and recorded.

Ethics approval was given by the local ethics committee (ID 082013), and written consents for study inclusion were obtained from all patients or their authorized representatives.

\section{Demographic data}

We collected demographic data, sex, age, weight, size, and body mass index (BMI). The following comorbidities were recorded to identify any relevant confounding factors for CSF leakage, infection, or impaired wound healing such as diabetes mellitus, arterial hypertension, anemia/thrombocytopenia, coronary heart disease, dermatitis, preoperative anticoagulation, and smoking.

\section{Operative methods}

All craniotomies were performed in the operating room using a laminar air flow system. Patients received compression stockings for prophylaxis of deep venous thrombosis, and subcutaneous heparin was started $24 \mathrm{~h}$ after surgery. The following prophylactic antibiotics were administered to all patients: cefuroxim $(1.5 \mathrm{~g})$, or-in case of penicillin allergyclindamycin $(600 \mathrm{mg})$ approximately $30 \mathrm{~min}$ before the start of the operation, and repeated every $3 \mathrm{~h}$ intraoperatively. Postoperative prophylactic antibiotics were not given. To prepare the scalp for incision, the scalp was shaved $(1-2 \mathrm{~cm}$ width along the marked incision), prepared by alcohol and iodine derivatives (Braunoderm ${ }^{\circledR}$, skin antiseptic, B. Braun Melsungen AG, Germany), and the surgical site was covered with a sterile transparent foil. At the end of the operation, meticulous hemostasis was ensured, followed by extradural irrigation (iodine and saline solution). Based on the individual surgeon's preference, a surgical silicone drain was placed subgalealy in the subgaleal drains group, then tunneled and delivered through a separate stab incision and attached to the closed drain system to gravity (Robdrain $®, 12 \mathrm{CH}$., outer diameter $4 \mathrm{~mm}$, length $100 \mathrm{~cm}, \mathrm{~B}$. Braun Melsungen AG, Melsungen, Germany). Standard wound closure was then performed by interrupted single sutures (subgaleal layer, subcutaneous layer), followed by closure of the skin (sutures or staples). Compressive dressings were used at the surgeon's discretion.

Following the surgery, the respective surgeon recorded all relevant technical aspects: type (curved/straight) and length of incision, technique of dural and skin closure (stitched or stapled), placement of subgaleal drains, and postoperative compressive dressing. Craniotomy reconstruction using titanium clamps $\left(\right.$ Craniofix $\left.{ }^{\circledR}\right)$ or polyester sutures $\left(\right.$ Mersilene $\left.{ }^{\circledR}\right)$ and intraoperative antiseptic irrigation (hydrogen peroxide or $1 \%$ povidone-iodine) were also documented. Intraoperative iatrogenic complications such as accidental opening of frontal 
sinuses or mastoid cells were also recorded. Craniotomy size was calculated with the maximum anterio-posterior (AP) and maximum cranio-caudal (CC) diameter with the consideration of the elliptic shape of craniotomies according to the following formula: $\pi \times(\mathrm{CC} / 2) \times(\mathrm{AP} / 2)$.

For comparative analysis, patients were then primarily stratified according to the presence or absence of nonsuction subgaleal drains (+drain, -drain) placed during closure. For comparative analysis, patients were then stratified according to the median of the craniotomy size $(\geq$ or $<$ $27 \mathrm{~cm}^{2}$ ) and length of the scalp incision ( $\geq$ or $\left.<15 \mathrm{~cm}\right)$.

\section{Postoperative management and outcome}

The surgical site was examined regularly with initial daily dressing changes. Compression bandage - if present-was removed $24 \mathrm{~h}$ postoperatively. Gravity drains were removed under sterile conditions when the flow rate was less than $100 \mathrm{ml}$ in the previous $24 \mathrm{~h}$, with all drains being removed after a maximum of $48 \mathrm{~h}$, closing the exit site with a single suture.

The following outcome parameters were recorded: presence of early periorbital edema graded as moderate or severe (eye opening impeded or not possible), presence of subgaleal swelling graded as moderate, or severe (including bulging and firm collections) at the time of discharge (early follow-up) and after 6 weeks (late follow-up), any impairment of wound healing (up to 6 weeks postoperatively) or any need for operative revision. Provided regular, primary wound healing, sutures, or staples were routinely removed on the 7 th -9 th postoperative day. In cases of wound breakdown (dehiscence of cutaneous layer, visibility of subcutaneous tissue or bone, hematoma, or cerebrospinal fluid leakage through the skin), the indication for operative revision was evaluated on an individual basis. Infection was defined as any of the following: evidence of a purulent wound, meningitis (verified by lumbar puncture), intracerebral abscess, or wound healing disorder in conjunction with increased inflammatory parameters (early or late follow-up).

Neurological examinations were performed daily and at time of discharge. The subjective pain level was assessed using the visual analogue scale (VAS).

\section{Statistical analysis}

Risk factor analysis was performed in two steps. Starting univariate logistic regression model, we identified variables that may influence outcome parameters. This step was used as a model building process, based on the decision rule, that factors showing a $p$ value of less or equal to 0.1 are used in the corresponding multivariate logistic regression model. In this last step, factors were assessed as significant, if the corresponding $p$ value fell below the 5\% margin. We reported our results by $p$ values, odds ratios and corresponding $95 \%$ confidence intervals $(\mathrm{Cl})$. Quantitative variables are summarized by mean and standard deviations (SD) and categorical data by absolute frequencies $(n)$ and percentages $(\%)$. In selected cases, chi square test was performed. All analyses were performed using IBM® SPSS® Statistics V22.0 (IBM, Chicago, Illinois, USA). Statistical significance was set at $p<0.05$, and statistical results with $p<0.1$ were accepted as a trend.

\section{Results}

\section{Demographic and surgical data}

A total of 150 craniotomies were performed for the following pathologies: tumor $(74.7 \% ; n=112)$, hematoma (subdural $6.7 \%, n=10$ or intraparenchymal $4.0 \%, n=6$ ), cerebrovascular disease (aneurysm, cavernoma, or arteriovenous malformations, $13.3 \% ; n=20)$, and unspecific lesions $(1.3 \%, n=2) .39 .3 \%$ of patients were male $(n=59)$, mean age of all cases was $59.1 \pm 14.8$ years.

The incision was performed in a straight line in $49.3 \%$ of patients and curved in the remaining $50.7 \%$, with an average length of $16.7 \pm 5.7 \mathrm{~cm}$ (median $15 \mathrm{~cm}$ ), resulting in short incisions in $57.7 \%(13.0 \pm 2.9 \mathrm{~cm})$ and longer incisions in $42.2 \%(21.7 \pm 4.8 \mathrm{~cm})$. We recorded an average size of craniotomy of $31.4 \pm 20.7 \mathrm{~cm}^{2}$ (median $27 \mathrm{~cm}^{2}$ ), resulting in $52.3 \%$ of smaller craniotomies $\left(18.0 \pm 6.6 \mathrm{~cm}^{2}\right)$ and $47.7 \%$ of larger craniotomies $\left(46.1 \pm 20.9 \mathrm{~cm}^{2}\right)$.

Intraoperative ventricle opening occurred in 14\% $(n=21)$; watertight closure with or without dural sealants was achieved in $77.3 \%(n=116)$, non-watertight dural closure in $22.7 \%$ $(n=34)$.

The majority of skin closures was performed using staples (70\%), and tendentially more often in cases with longer skin incisions $(p=0.069)$, but not with larger craniotomies ( $p=$ 0.383). Compressive dressing was used in $33.3 \%$ of cases and did not depend on the length of incision or the size of the craniotomy ( $p=0.889, p=0.274$, data not shown).

For the subgroup analysis, we identified 112 patients undergoing surgery for neoplastic disease; this group was further stratified according to neoplastic entity, size, and localization (Suppl. Table 1).

\section{Association of subgaleal drainage and other surgical variables}

Subgaleal drains were used in $42 \%$ of cases. Patients with and without drains (+drain vs -drain) were comparable in terms of basic demographic data and clinical features. Patients with longer incisions and larger craniotomies received drains significantly more often (incision $>15 \mathrm{~cm}$ : +drain $67.7 \%$ vs -drain $24.1 \%, p<0.0001$; craniotomy $>27 \mathrm{~cm}^{2}$ : +drain 
$62.9 \%$ vs -drain $36.8 \%, p<0.01$ ). With watertight dural closure with or without sealants, drains were placed significantly more often (+drain $88.9 \%$ vs -drain $69.0 \%, p<0.01$ ); wounds were significantly more often closed with stables, when a drain was used (+drain $87.3 \%$ vs -drain $57.5 \%, p<0.0001$ ). Patients with subgaleal drains received compressive dressings more frequently (+drain $47.4 \%$ vs -drain $23.5 \%, p<0.01$ ) (Table 1).

\section{Postoperative course and outcome parameter}

Early periorbital edema was observed in $10 \%(n=15)$ of cases. $34.8 \%(n=55)$ of patients developed early subgaleal swelling (moderate and severe), which persisted in $2.3 \%$ $(n=3)$ at late follow-up. Two of these cases had to undergo operative revision. In $3.3 \%(n=5)$ of cases, wound healing was impaired, and a total of $6.7 \%(n=10)$ had to undergo any kind of operative procedure (puncture, secondary stitches, or operative revision). Adequate pain control was achieved in $90.4 \%$ of patients in the early follow-up and in $97.5 \%$ in the late follow-up.

\section{Association of subgaleal drainage and outcome}

The effect of drainage on recorded outcome parameters was analyzed using the binary logistic regression model. The incidence of periorbital edema (moderate or severe), subgaleal swelling (moderate and severe, early and late), impaired wound healing (until late follow-up), non-adequate pain control (early and late $\mathrm{f} / \mathrm{u}$ ), and need for operative revision was not affected by the presence of subgaleal drains $(p=0.115$, $p=0.515, p=0.395, p=0.927, p=0.927, p=0.586, p=$ $0.388, p=0.895$ ) (Table 2). Early pain control (VAS $0-4$ ) was acceptable in both groups (1st day postoperative: + drain $91.2 \%$ vs -drain $91.8 \%, p=0.607$; 3rd day postoperative: +drain $88.6 \%$ vs -drain $89.8 \% p=0.564$ ) (data not shown in tables). Tumor entity did not influence the decision to the placement of subgaleal drains. After additional subgroup analysis, larger tumor size was significantly associated with higher infection rate $(p=0.043)$ with more infections related to metastasis $(p=0.017)$ (Suppl. Table 2). In this context, subgaleal drains did not influence the infection rate.

\section{Effect of other surgical variables on outcome}

To identify the effect of other surgical variables on outcome, the same regression model approach was selected as described above. Early periorbital edema was not affected by any of the surgical parameter (length of incision, shape of the incision, craniotomy size, intraoperative ventricle opening, type of dural or wound closure, and presence of compressive dressing). Subgaleal swelling (early f/u) occurred more frequently in cases with longer wound incision (OR 1.104, 95\% CI $1.035-1.178, p=0.003$ ), curved wound incision (OR 3.821, $95 \%$ CI $1.873-7.797, p<0.0001)$ and larger craniotomy size (OR 1.040, 95\% CI 1.018-1.062, $p<0.001$ ). Larger tumor size was associated with an increase in early CSF or hematoma collection $(p<0.01)$ but lost his significant in the late follow-up $(p=0.365)$.

Based on the corresponding multivariate logistic regression model, the significantly higher rate of subgaleal swelling at the early $\mathrm{f} / \mathrm{u}$ was only linked to larger craniotomy size (OR $1.032,95 \%$ CI $1.006-1.059, p<0.05)$ and selection of curved incisions (OR $0.336,95 \%$ CI $0.156-0.723, p<0.01$ ), but was not related to the incision length (OR 1.008 , 95\% CI 0.926 $1.097, p=0.859$ ), (data not shown in tables).

Table 1 Surgical variables for all patients, as well as in the presence and absence of subgaleal drains (+drain, - drain)

\begin{tabular}{|c|c|c|c|c|c|}
\hline \multicolumn{2}{|c|}{ Surgical variables } & \multicolumn{4}{|c|}{$n(\%)$ or mean $\pm \mathrm{SD}$} \\
\hline Access & Curved: straight incision & $\begin{array}{l}76(50.7 \%) \\
74(49.3 \%)\end{array}$ & $\begin{array}{l}43(68.3 \%) \\
20(31.7 \%)\end{array}$ & $\begin{array}{l}33(37.9 \%) \\
54(62.1 \%)\end{array}$ & $p<0.0001$ \\
\hline & $\begin{array}{l}\text { Longer incision } \geq 15 \mathrm{~cm} \\
\text { Shorter incision }<15 \mathrm{~cm}\end{array}$ & $\begin{array}{l}63(42.2 \%) \\
86(57.7 \%)\end{array}$ & $\begin{array}{l}42(67.7 \%), \\
20(32.3 \%)\end{array}$ & $\begin{array}{l}21(24.1 \%) \\
66(75.9 \%)\end{array}$ & $p<0.0001$ \\
\hline & $\begin{array}{l}\text { Larger craniotomy } \geq 27 \mathrm{~cm}^{2} \\
\text { Smaller craniotomy }<27 \mathrm{~cm}^{2}\end{array}$ & $\begin{array}{l}71(47.7 \%), \\
78(52.3 \%)\end{array}$ & $\begin{array}{l}39(62.9 \%), \\
23(37.1 \%)\end{array}$ & $\begin{array}{l}32(36.8 \%), \\
55(63.2 \%)\end{array}$ & $p<0.01$ \\
\hline \multicolumn{2}{|c|}{ Intraoperative ventricle opening } & $21(14 \%)$ & $8(12.7 \%)$ & $13(14.9 \%)$ & ns \\
\hline \multirow[t]{2}{*}{ Closure } & $\begin{array}{l}\text { non-watertight dural closure: watertight dural } \\
\text { closure with or without sealants } \\
\text { suture: staples }\end{array}$ & $\begin{array}{l}34(22.7 \%) \\
116(77.3) \\
45(30 \%) \\
105(70 \%)\end{array}$ & $\begin{aligned} & 7(11.1 \%), \\
& 56(88.9 \%) \\
& 8(12.7 \%), \\
& 55(87.3 \%)\end{aligned}$ & $\begin{array}{l}27(31.0 \%), \\
60(69.0 \%) \\
37(42.5 \%), \\
50(57.5 \%)\end{array}$ & $\begin{array}{l}p<0.01 \\
p<0.0001\end{array}$ \\
\hline & compressive dressing & $46(30.7 \%)$ & $27(42.9 \%)$ & $19(21.8 \%)$ & $p<0.01$ \\
\hline
\end{tabular}

$P$-values are calculated for surgical variables after stratifying in two groups (+drain vs - drain). Patients with curved incisions, longer incisions, and larger craniotomies received drains significantly more often. With watertight dural closure with or without sealants, drains were placed significantly more often; wounds were significantly more often closed with stables, when a drain was used. Patients with subgaleal drains received compressive dressings more frequently

+drain, patient with subgaleal drainage; -drain, patient without subgaleal drainage; $n s$, not significant; $S D$, standard deviation 
Table 2 Univariate regression analysis of outcome parameters with and without drainage

\begin{tabular}{|c|c|c|c|c|c|c|}
\hline \multirow[t]{2}{*}{ Outcome parameter } & \multirow{2}{*}{$\begin{array}{l}\text { Total } \\
n(\%) \text { or } \\
\text { mean } \pm \mathrm{SD}\end{array}$} & \multirow[t]{2}{*}{+ Drain } & \multirow[t]{2}{*}{- Drain } & \multicolumn{3}{|c|}{ Logistic regression } \\
\hline & & & & OR & $95 \% \mathrm{CI}$ & $p$ value \\
\hline $\begin{array}{l}\text { Periorbital edema } \\
\text { (early; moderate or severe) }\end{array}$ & $9(10.0 \%)$ & $6(16.2 \%)$ & $3(5.7 \%)$ & 0.310 & $0.072-1.330$ & ns \\
\hline $\begin{array}{l}\text { Subgaleal swelling } \\
\text { (early) }\end{array}$ & $55(36.7 \%)$ & $25(39.7 \%)$ & $30(34.5 \%)$ & 0.800 & $0.409-1.565$ & $\mathrm{~ns}$ \\
\hline $\begin{array}{l}\text { Subgaleal swelling } \\
\text { (late) }\end{array}$ & $3(2.3 \%)$ & $2(3.6 \%)$ & $1(1.3 \%)$ & 0.349 & $0.031-3.945$ & ns \\
\hline Impaired wound healing & $5(3.3 \%)$ & $2(3.2 \%)$ & $3(3.4 \%)$ & 1.089 & $0.177-6.718$ & ns \\
\hline Pain, VAS 5-10 (early) & $8(9.6 \%)$ & $4(11.8 \%)$ & $4(8.2 \%)$ & 0.667 & $0.155-2.873$ & ns \\
\hline Pain, VAS 5-10 (late) & $3(2.5 \%)$ & $2(4.0 \%)$ & $1(1.4 \%)$ & 0.343 & $0.030-3.888$ & ns \\
\hline Need for operative revision & $10(6.7 \%)$ & $4(6.3 \%)$ & $6(6.9 \%)$ & 1.093 & $0.295-4.045$ & ns \\
\hline Infection & $11(7.3 \%)$ & $4(6.3 \%)$ & $7(8.0 \%)$ & 1.291 & $0.361-4.613$ & ns \\
\hline
\end{tabular}

The effect of drainage on recorded outcome parameters was analyzed using the binary logistic regression model. Outcome parameter at the time of discharge was decelerated as early follow-up; after 6 weeks, as late follow-up. The incidence of periorbital edema (moderate or severe), subgaleal swelling (moderate and severe, early and late), impaired wound healing (until late follow-up), non-adequate pain control (early and late f/u), need for operative revision, and infection was not affected by the presence of subgaleal drains. Infection was defined as any of the following: evidence of a purulent wound, meningitis (verified by lumbar puncture), intracerebral abscess, or wound healing disorder in conjunction with increased inflammatory parameters (early or late follow-up).

$C I$, confidence interval; +drain, patient with subgaleal drainage; -drain, patient without subgaleal drainage; $n s$, not significant; $O R$, odds ratio; $S D$, standard deviation; VAS, visual analog scale

Late clinical follow-up was available in $88 \%$ of patients. At late follow-up, subgaleal swelling persisted in patients with larger craniotomies (OR 1.040, 95\% CI 1.001-1.080, $p=$ $0.047)$. At the early and late follow-up, postoperative infections were found in $7.3 \%$ of cases and were not affected by any of the recorded surgical variables. No further relevant differences were observed, and this was confirmed also when only including patients undergoing surgery for neoplastic diseases (Suppl. Table 2).

\section{Discussion}

According to the literature, postoperative complications after craniotomies such as intra- or extracranial bleeding, leakage of cerebrospinal fluid (CSF) [32, 40], impaired wound healing, and frank wound infection are infrequently observed, but nevertheless increase morbidity rate $[1,20,29,37]$ as well as socioeconomic costs after surgeries $[1,37]$ considerably. Subgaleal hematomas and fluid collections as such occur more often after cranial surgery and are believed to increase both patient discomfort as well as the overall postoperative complication rate. Historically, the use of subgaleal drains was first described by Ames et al. [3]. Drains may decrease the rate of postoperative fluid collections and other complications, and - as a consequence - are employed by several surgeons, while the objective benefit is still unclear $[8,30]$.

\section{Effect of prophylactic antibiotics on clinical course}

As recommended by the clinical practice guidelines in surgery, we routinely administer prophylactic preoperative antibiotics in all craniotomies [10]. While routine administration of postoperative antibiotics is common practice in many institutions, the risk of surgical site infection (SSI) remains unaffected $[6,22,24,27,46]$.

The use of postoperative antibiotics did not belong to the standard operating procedure in our clinic as they seem to be associated with drawbacks including allergic reaction, gastrointestinal upset, infection with Clostridium difficile, or other resistant organisms and can increase in-hospital costs [18, 23].

\section{Possible complications and side effects after placement of subgaleal drains}

The placement of subgaleal drains with or without suction is often dependent on the experiences or preferences of the surgeons and/or intraoperative findings [11], the underlying hypothesis being the reduction subgaleal collection, thus avoiding wound tension, pain, and possibly (super) infection. However, previous studies suggest that the complication rate is not reduced after supratentorial craniotomies, but can include bradycardia $[15,28,48]$, asystole $[9,52]$, bleeding from the superior sagittal sinus [35], epidural hematomas [11, 41, 49], pseudohypoxic brain swelling with fatal courses [49], and 
sudden intracranial pressure drop with rupture of a partially clipped aneurysm [39]. While in most of the abovementioned, catastrophic incidences, subgaleal drainages on suction were used, open gravity drainage can result in comparable suction effect when placed below body level. Other negative aspects of using subgaleal drains include increased economic costs, the necessity of and discomfort when removing drains, headache, and anxiety. Fresh blood clots may even impede the functionality of drains, with persistent subgaleal fluid collections. In the context of spine surgery or orthopedic operations, placement of drains does not seem to prevent postoperative epidural bleeding and overall infection rate, though an increase in patient discomfort is noted [14, 38, 45, 54]. After abdominal surgery (laparotomy), Higson et al. found a duplication of infection using non-aspirating drainage, whereas other studies did not confirm this association [25]. Drains can generally lead to a reduction in pain after surgeries such as total knee arthroplasty, but the results in this randomized prospective study were only confirmed in the early-term but not long-term follow-up [17]. However, in considering the postoperative pain in other disciplines, Schietroma et al. found that routine drain placement after thyroidectomy is not necessary, and avoiding drainage was associated with less postoperative pain [44]. The controversial results in between the trials mentioned above lead ultimately to different conclusions which are possibly subject-specific.

Due to the conflicting results and findings of previous studies and the strong personal belief of treating physicians, it was the purpose of this observational study to determine the effect - if any — of surgical nuances and preferences (type of wound closure and use of drains) on the postoperative course after supratentorial craniotomy.

\section{Effect of subgaleal drains on recorded outcome parameters}

In our cohort, the infection rate was $7.3 \%$, corresponded well with findings of other groups (infection rate between 1 and $11 \%)[1,16,33,37]$ and was comparable in patients with and without drains; further surgical parameters did not affect the infection rate. The presence of drains was not associated with a difference in wound healing or the need for operative revision but also did not decrease periorbital edema or subgaleal swelling nor the postoperative perception of pain, as initially hypothesized.

\section{Effect of other surgical variables on outcome parameters}

Regarding supratentorial craniotomies, our results are in line with other studies that the watertight dural closure is not necessarily associated with an increased rate of complications [7, 42]. Even in the case of larger surgeries such as decompressive craniectomies, complications related to non-watertight dural closure seem to be negligible $[21,50]$, and may be more related to quality and technique of skin closure. We did not observe differences in outcome caused by skin closure techniques using staples or stitches. However, the workgroup Abu Hamed et al. described significantly increased infection rates related to the use of staples instead of sutures [1], though possibly inherent to study design and not reproduced in our observational analysis. John et al. 2017 [26] reported a negative influence on outcome in patient with ventricle opening during tumor surgery, an effect that was not observed in our cohort. A possible explanation for this discrepancy may be the heterogeneity of our cohort and the limited number of patients with intracranial tumor surgeries with intraoperative ventricle opening.

It can be speculated that placement of a drain and the use of compressive dressings are more common in younger, possibly less experienced surgeons under the assumption of avoiding postoperative complications. Though our analysis did not include stratification by experience and years of practice, the use of drains according to personal preference appears acceptable, as the associated complication rate was not higher, even in the presence of larger and possibly more hazardous craniotomies.

\section{Limitations}

Our study is limited due to the observational nature of the design. The monocentric, non-randomized analysis does not readily allow generalization or extrapolation to other centers. There is an inherent selection bias, and we can only confirm that accommodating the individual surgeon's preference/ nuance in our center resulted in comparable outcome.

In general, subgaleal drains can be placed based on the preference of surgeons whereby the advantage of drains could not be ensured by the present study for any of the recorded subjective and objective outcome parameters. At the same time, recorded operative nuances do not appear to play a major role in determining outcome, thus it is questionable, whether larger prospective studies are justified.

\section{Conclusions}

Permissive attitudes towards surgical nuances and preferences - including the use of subgaleal drains and differences in dural closure - can result in comparable outcome after supratentorial craniotomies.

Authors' contribution Conceived, designed, and performed the study: HAH, GAS, WA. Analyzed the data: HAH, CW, GAS, WA. Wrote the manuscript: HAH. Critical review of the manuscript: KK, SKT, CB, HC, GAS, WA. 
Funding Information Open Access funding provided by Projekt DEAL.

\section{Compliance with ethical standards}

Conflict of interest The authors declare that they have no conflict of interest.

Ethical approval The work has been carried out in accordance with the code of ethics of the World Medical Association (Declaration of Helsinki) for experiments involving humans. Ethics approval was given by the local ethics committee (ID 082013).

Open Access This article is licensed under a Creative Commons Attribution 4.0 International License, which permits use, sharing, adaptation, distribution and reproduction in any medium or format, as long as you give appropriate credit to the original author(s) and the source, provide a link to the Creative Commons licence, and indicate if changes were made. The images or other third party material in this article are included in the article's Creative Commons licence, unless indicated otherwise in a credit line to the material. If material is not included in the article's Creative Commons licence and your intended use is not permitted by statutory regulation or exceeds the permitted use, you will need to obtain permission directly from the copyright holder. To view a copy of this licence, visit http://creativecommons.org/licenses/by/4.0/

\section{References}

1. Abu Hamdeh S, Lytsy B, Ronne-Engstrom E (2014) Surgical site infections in standard neurosurgery procedures- a study of incidence, impact and potential risk factors. Br J Neurosurg 28:270 275. https://doi.org/10.3109/02688697.2013.835376

2. Ahn JY, Kim SH (2009) A new technique for dural suturing with fascia graft for cerebrospinal fluid leakage in transsphenoidal surgery. Neurosurgery 65:65-71; discussion 71-62. https://doi.org/10. 1227/01.NEU.0000327695.32775.BB

3. Ames RH (1967) Ventriculo-peritoneal shunts in the management of hydrocephalus. J Neurosurg 27:525-529. https://doi.org/10. 3171/jns.1967.27.6.0525

4. Barami K, Fernandes R (2012) Incidence, risk factors and management of delayed wound dehiscence after craniotomy for tumor resection. J Clin Neurosci 19:854-857. https://doi.org/10.1016/j.jocn. 2011.09.025

5. Barker FG 2nd (2007) Efficacy of prophylactic antibiotics against meningitis after craniotomy: a meta-analysis. Neurosurgery 60: 887-894; discussion 887-894. https://doi.org/10.1227/01.NEU. 0000255425.31797.23

6. Bartella AK, Lemmen S, Burnic A, Kloss-Brandstatter A, Kamal M, Breisach T, Holzle F, Lethaus B (2018) Influence of a strictly perioperative antibiotic prophylaxis vs a prolonged postoperative prophylaxis on surgical site infections in maxillofacial surgery. Infection 46:225-230. https://doi.org/10.1007/s15010-017-1110-4

7. Barth M, Tuettenberg J, Thome C, Weiss C, Vajkoczy P, Schmiedek P (2008) Watertight dural closure: is it necessary? A prospective randomized trial in patients with supratentorial craniotomies. Neurosurgery 63:352-358; discussion 358. https://doi.org/10. 1227/01.NEU.0000310696.52302.99

8. Beer KJ, Lombardi AV Jr, Mallory TH, Vaughn BK (1991) The efficacy of suction drains after routine total joint arthroplasty. J Bone Joint Surg Am 73:584-587

9. Bhagat H, Mangal K, Jain A, Sinha R, Mallik V, Gupta SK, Sethi S (2012) Asystole following craniotomy closure: yet another complication of negative-pressure suctioning of subgaleal drain. Indian J Anaesth 56:304-305. https://doi.org/10.4103/0019-5049. 98787

10. Bratzler DW, Dellinger EP, Olsen KM, Perl TM, Auwaerter PG, Bolon MK, Fish DN, Napolitano LM, Sawyer RG, Slain D, Steinberg JP, Weinstein RA, American Society of Health-System P, Infectious Disease Society of A, Surgical Infection S, Society for Healthcare Epidemiology of A (2013) Clinical practice guidelines for antimicrobial prophylaxis in surgery. Am J Health Syst Pharm 70:195-283. https://doi.org/10.2146/ajhp120568

11. Choi SY, Yoon SM, Yoo CJ, Park CW, Kim YB, Kim WK (2015) Necessity of surgical site closed suction drain for Pterional craniotomy. J Cerebrovasc Endovasc Neurosurg 17:194-202. https://doi. org/10.7461/jcen.2015.17.3.194

12. Cosgrove GR, Delashaw JB, Grotenhuis JA, Tew JM, Van Loveren H, Spetzler RF, Payner T, Rosseau G, Shaffrey ME, Hopkins LN, Byrne R, Norbash A (2007) Safety and efficacy of a novel polyethylene glycol hydrogel sealant for watertight dural repair. J Neurosurg 106:52-58. https://doi.org/10.3171/jns.2007.106.1.52

13. Dashti SR, Baharvahdat H, Spetzler RF, Sauvageau E, Chang SW, Stiefel MF, Park MS, Bambakidis NC (2008) Operative intracranial infection following craniotomy. Neurosurg Focus 24:E10. https:// doi.org/10.3171/FOC/2008/24/6/E10

14. Davidoff CL, Rogers JM, Simons M, Davidson AS (2018) A systematic review and meta-analysis of wound drains in noninstrumented lumbar decompression surgery. J Clin Neurosci 53: 55-61. https://doi.org/10.1016/j.jocn.2018.04.038

15. Demetriades AK (2008) Negative pressure suction from subgaleal drainage: bradycardia and decreased consciousness. Acta Neurochir 150:1111. https://doi.org/10.1007/s00701-008-0028-0

16. Erman T, Demirhindi H, Gocer AI, Tuna M, Ildan F, Boyar B (2005) Risk factors for surgical site infections in neurosurgery patients with antibiotic prophylaxis. Surg Neurol 63:107-112; discussion 112-103. https://doi.org/10.1016/j.surneu.2004.04.024

17. Erne F, Wetzel S, Wulker N, Gesicki M, Hofmann UK (2018) Closed suction drainage after primary total knee arthroplasty: a prospective randomized trial. J Knee Surg 31:804-810. https:// doi.org/10.1055/s-0037-1615297

18. Fry DE (2008) Surgical site infections and the surgical care improvement project (SCIP): evolution of national quality measures. Surg Infect 9:579-584. https://doi.org/10.1089/sur.2008.9951

19. Gazzeri R, Galarza M, Neroni M, Canova A, Refice GM, Esposito S (2007) Continuous subgaleal suction drainage for the treatment of chronic subdural haematoma. Acta Neurochir 149:487-493; discussion 493. https://doi.org/10.1007/s00701-007-1139-8

20. Grotenhuis JA (2005) Costs of postoperative cerebrospinal fluid leakage: 1-year, retrospective analysis of 412 consecutive nontrauma cases. Surg Neurol 64:490-493, discussion 493-494. https://doi.org/10.1016/j.surneu.2005.03.041

21. Guresir E, Vatter H, Schuss P, Oszzald A, Raabe A, Seifert V, Beck J (2011) Rapid closure technique in decompressive craniectomy. J Neurosurg 114:954-960. https://doi.org/10.3171/2009.12.JNS091065

22. Haider M, Ladurner C, Mayr R, Tandogdu Z, Fritsche HM, Fradet V, Comploj E, Pycha A, Lemire F, Lacombe L, Fradet Y, Toren P, Lodde M (2019) Use and duration of antibiotic prophylaxis and the rate of urinary tract infection after radical cystectomy for bladder cancer: Results of a multicentric series. Urol Oncol 37:300 e309300 e315. https://doi.org/10.1016/j.urolonc.2019.01.017

23. Hauser CJ, Adams CA Jr, Eachempati SR, Council of the Surgical Infection S (2006) Surgical infection society guideline: prophylactic antibiotic use in open fractures: an evidence-based guideline. Surg Infect 7:379-405. https://doi.org/10.1089/sur.2006.7.379

24. Hochreiter M, Uhling M, Sisic L, Bruckner T, Heininger A, Hohn A, Ott K, Schmidt T, Berger MM, Richter DC, Buchler M, Weigand MA, Busch CJ (2018) Prolonged antibiotic prophylaxis after thoracoabdominal esophagectomy does not reduce the risk of 
pneumonia in the first 30 days: a retrospective before-and-after analysis. Infection 46:617-624. https://doi.org/10.1007/s15010018-1160-2

25. Imada S, Noura S, Ohue M, Shingai T, Sueda T, Kishi K, Yamada T, Ohigashi H, Yano M, Ishikawa O (2013) Efficacy of subcutaneous penrose drains for surgical site infections in colorectal surgery. World J Gastrointest Surg 5:110-114. https://doi.org/10.4240/ wjgs.v5.i4.110

26. John JK, Robin AM, Pabaney AH, Rammo RA, Schultz LR, Sadry NS, Lee IY (2017) Complications of ventricular entry during craniotomy for brain tumor resection. J Neurosurg 127:426-432. https://doi.org/10.3171/2016.7.JNS16340

27. Kalkanli A, Gezmis CT, Ozkan A, Cilesiz NC, Yanaral F, Aydin M, Tandogdu Z (2018) Comparison of single and prolonged fluoroquinolone prophylaxis and risk factors for infectious complications after transrectal prostate biopsy. Balkan Med J 35:373-377. https:// doi.org/10.4274/balkanmedj.2018.0477

28. Karamchandani K, Chouhan RS, Bithal PK, Dash HH (2006) Severe bradycardia and hypotension after connecting negative pressure to the subgaleal drain during craniotomy closure. $\mathrm{Br} \mathrm{J}$ Anaesth 96:608-610. https://doi.org/10.1093/bja/ael063

29. Kim KD, Wright NM (2011) Polyethylene glycol hydrogel spinal sealant (DuraSeal spinal sealant) as an adjunct to sutured dural repair in the spine: results of a prospective, multicenter, randomized controlled study. Spine (Phila Pa 1976) 36:1906-1912. https://doi. org/10.1097/BRS.0b013e3181fdb4db

30. Kim YH, Cho SH, Kim RS (1998) Drainage versus nondrainage in simultaneous bilateral total hip arthroplasties. J Arthroplast 13:156-161

31. Kumar A, Maartens NF, Kaye AH (2003) Evaluation of the use of BioGlue in neurosurgical procedures. J Clin Neurosci 10:661-664

32. Mantur M, Lukaszewicz-Zajac M, Mroczko B, Kulakowska A, Ganslandt O, Kemona H, Szmitkowski M, Drozdowski W, Zimmermann R, Kornhuber J, Lewczuk P (2011) Cerebrospinal fluid leakage-reliable diagnostic methods. Clin Chim Acta 412: 837-840. https://doi.org/10.1016/j.cca.2011.02.017

33. McClelland S 3rd, Hall WA (2007) Postoperative central nervous system infection: incidence and associated factors in 2111 neurosurgical procedures. Clin Infect Dis 45:55-59. https://doi.org/10. $1086 / 518580$

34. Mohamed EE (2003) Chronic subdural haematoma treated by craniotomy, durectomy, outer membranectomy and subgaleal suction drainage. Personal experience in 39 patients. Br J Neurosurg 17: 244-247

35. Mohindra S, Mukherjee KK, Chhabra R, Khosla VK (2005) Subgaleal suction drain leading to fatal sagittal sinus haemorrhage. Br J Neurosurg 19:352-354. https://doi.org/10.1080/ 02688690500305308

36. Nakajima S, Fukuda T, Hasue M, Sengoku Y, Haraoka J, Uchida T (2001) New technique for application of fibrin sealant: rubbing method devised to prevent cerebrospinal fluid leakage from dura mater sites repaired with expanded polytetrafluoroethylene surgical membranes. Neurosurgery 49:117-123

37. O'Keeffe AB, Lawrence T, Bojanic S (2012) Oxford craniotomy infections database: a cost analysis of craniotomy infection. Br J Neurosurg 26:265-269. https://doi.org/10.3109/02688697.2011.626878

38. Parker MJ, Roberts C (2001) Closed suction surgical wound drainage after orthopaedic surgery. Cochrane Database Syst Rev: CD001825. https://doi.org/10.1002/14651858.CD001825

39. Prabhakar H, Bithal PK, Chouhan RS, Dash HH (2008) Rupture of intracranial aneurysm after partial clipping due to aspiration drainage system-a case report. Middle East J Anaesthesiol 19:1185-1190

40. Rotenberg BW, Marchie A, Cusimano MD (2004) Skin sealants: an effective option for closing cerebrospinal fluid leakage. Can J Surg $47: 466-468$
41. Roth J, Galeano E, Milla S, Hartmannsgruber MW, Weiner HL (2011) Multiple epidural hematomas and hemodynamic collapse caused by a subgaleal drain and suction-induced intracranial hypotension: case report. Neurosurgery 68:E271-E275; discussion E276. https://doi.org/10.1227/NEU.0b013e3181fe6165

42. Roth J, Benvenisti H, Constantini S (2018) Watertight dural closure in pediatric craniotomies-is it really necessary? World Neurosurg 114:e743-e746. https://doi.org/10.1016/j.wneu.2018.03.070

43. Sakamoto N, Akutsu H, Takano S, Yamamoto T, Matsumura A (2013) Useful 'sliding-lock-knot' technique for suturing dural patch to prevent cerebrospinal fluid leakage after extended transsphenoidal surgery. Surg Neurol Int 4:19. https://doi.org/10. 4103/2152-7806.107546

44. Schietroma M, Pessia B, Bianchi Z, De Vita F, Carlei F, Guadagni S, Amicucci G, Clementi M (2017) Thyroid surgery: to drain or not to drain, that is the problem - a randomized clinical trial. ORL $\mathrm{J}$ Otorhinolaryngol Relat Spec 79:202-211. https://oi.org/10.1159/ 000464137

45. Schubert GA, Diepers M, Hegewald AA, Seiz M, Thomé C (2013) Routine postoperative imaging early after lumbar decompression surgery: a prospective evaluation. Spine (Phila Pa 1976) 38: E1263-E1268. https://doi.org/10.1097/BRS.0b013e31829fc6a6

46. Tang R, Chen HH, Wang YL, Changchien CR, Chen JS, Hsu KC, Chiang JM, Wang JY (2001) Risk factors for surgical site infection after elective resection of the colon and rectum: a single-center prospective study of 2809 consecutive patients. Ann Surg 234: 181-189. https://doi.org/10.1097/00000658-200108000-00007

47. Tong JW, Emelin JK, Wong R, Meltzer HS, Cohen SR (2015) Subgaleal drain placement improves surgical outcomes after primary cranioplasty in craniosynostosis patients. J Craniofac Surg 26: 1963-1966. https://doi.org/10.1097/SCS.0000000000001224

48. Toshniwal GR, Bhagat H, Rath GP (2007) Bradycardia following negative pressure suction of subgaleal drain during craniotomy closure. Acta Neurochir 149:1077-1079; discussion 1079. https://doi. org/10.1007/s00701-007-1246-6

49. Van Roost D, Thees C, Brenke C, Oppel F, Winkler PA, Schramm J (2003) Pseudohypoxic brain swelling: a newly defined complication after uneventful brain surgery, probably related to suction drainage. Neurosurgery 53:1315-1326 discussion 1326-1317

50. Vieira E, Guimaraes TC, Faquini IV, Silva JL, Saboia T, Andrade R, Gemir TL, Neri VC, Almeida NS, Azevedo-Filho HRC (2018) Randomized controlled study comparing 2 surgical techniques for decompressive craniectomy: with watertight duraplasty and without watertight duraplasty. J Neurosurg 129:1017-1023. https://doi.org/ 10.3171/2017.4.JNS152954

51. Weinstein JS, Liu KC, Delashaw JB Jr, Burchiel KJ, van Loveren HR, Vale FL, Agazzi S, Greenberg MS, Smith DA, Tew J Jr (2010) The safety and effectiveness of a dural sealant system for use with nonautologous duraplasty materials. J Neurosurg 112:428-433. https://doi.org/10.3171/2009.6.JNS081540

52. Yadav M, Nikhar SA, Kulkarni DK, Gopinath R (2014) Cardiac arrest after connecting negative pressure to the subgaleal drain during craniotomy closure. Case Rep Anesthesiol 2014:146870. https://doi.org/10.1155/2014/146870

53. Yoshimoto T, Sawamura Y, Houkin K, Abe H (1997) Effectiveness of fibrin glue for preventing postoperative extradural fluid leakage. Neurol Med Chir (Tokyo) 37:886-889 discussion 889-890

54. Zijlmans JL, Buis DR, Verbaan D, Vandertop WP (2016) Wound drains in non-complex lumbar surgery: a systematic review. Bone Joint J 98-B:984-989. https://doi.org/10.1302/0301-620X.98B7. 37190

Publisher's note Springer Nature remains neutral with regard to jurisdictional claims in published maps and institutional affiliations. 